\title{
Promovendo exportações de móveis: aspectos da implementação do PROMÓVEL no aglomerado moveleiro de São Bento do Sul (SC)
}

Hoyêdo Nunes Lins ${ }^{1}$

Priscila Azevedo Guimarães ${ }^{2}$

Resumo: O artigo focaliza a implementação do Programa Brasileiro de Incremento às Exportações de Móveis (PROMÓVEL) na área de São Bento do Sul (SC), de grande destaque nas exportações brasileiras de móveis. Baseado em entrevistas, realizadas em janeiro de 2007 em empresas e instituições, o texto argumenta que o programa não foi bem sucedido localmente devido à escassez de motivação e interesse das empresas e aos problemas que surgiram no processo. Um ensinamento importante é que programas desse tipo devem ser adaptados às condições locais, em vez de implementados como se tivessem validade geral.

Palavras-chave: Setor moveleiro; São Bento do Sul (SC); promoção das exportações.

\section{Promoting furniture exports: on the implementation of Promóvel in São Bento do Sul, Santa Catarina State}

\footnotetext{
Abstract: The article focuses on the implementation of the Brazilian Program for Increasing Furniture Exports (PROMÓVEL) in the area of São Bento do Sul (Santa Catarina State), which is very important in furniture exports. Based upon interviews performed in January 2007 in firms and institutions, the article argues that PROMÓVEL has not succeeded locally due to lack of motivation and interest

1 Professor Titular do Departamento de Ciências Econômicas da Universidade Federal de Santa
Catarina e membro do corpo permanente de docentes do Programa de Pós-Graduação em Economia
dessa universidade. E-mail: hnlins@cse.ufsc.br.
2 Economista graduada na Universidade Federal de Santa Catarina. E-mail: prikaag@yahoo.com.br.
} 
from the firms and also to problems of implementation. A crucial learning is that programs of this kind must be adapted to local conditions, instead of implemented as if their general structures could be applied everywhere.

Keywords: Furniture sector; São Bento do Sul (SC); exports promotion.

JEL: L79

\section{Introdução}

O Brasil não é um grande player no comércio mundial de móveis, embora o passado recente tenha registrado uma expansão pronunciada das correspondentes receitas de exportação. Visando melhorar a inserção do país nesse mercado, um grupo de instituições - de representação e defesa dos interesses da indústria, órgãos públicos de status ministerial e/ou voltados ao fomento - concebeu e implantou, no final da década passada, o Programa Brasileiro de Incremento às Exportações de Móveis (PROMÓVEL). Essa iniciativa ocorreu em contexto de desaceleração do crescimento geral das exportações brasileiras, no final da década passada, tornando necessário um "novo conjunto de ações coordenadas de governo, de suas entidades financeiras, de suas máquinas administrativas e de seus órgãos de fomento para que, em conjunto com as associações de classe (...)" (Lima et al. 2000: 255-256), se pudesse favorecer um salto exportador. Escolher alvos, como regiões e setores (Lima et al. 1999), desenvolver a cultura exportadora e capacitar as empresas, privilegiando as de pequeno e médio porte (PMEs), pareciam procedimentos estratégicos. É nessa perspectiva que devem ser olhadas as ações que frutificaram no PROMÓVEL e em outros instrumentos parecidos, como o Programa Nacional de Estímulo à Exportação de Software, o SOFTEX.

Este artigo tem como objeto o papel desempenhado pelo PROMÓVEL no aglomerado de produção moveleira de São Bento do Sul, responsável, dentre todos os aglomerados brasileiros do gênero, pela maior fatia dos respectivos valores exportados. A abordagem apóia-se em pesquisa de campo, com entrevistas em empresas participantes e contatos em instituições locais. As entrevistas foram realizadas em janeiro de 2007 num painel de nove empresas, quatro de porte médio e cinco de pequeno porte (ver anexo): cinco no Município de São Bento do Sul, três no Município de Rio Negrinho e uma no Município de Campo Alegre, em cujos territórios se desdobra o referido aglomerado. Nenhuma dessas empresas pertence ao grupo das mais importantes da área. Isso tem a ver com o espírito da pesquisa, que almejava perceber a maneira como um programa criado para estimular as exportações reverberou junto a fabri- 
cantes que não estão entre os mais conhecidos do principal aglomerado moveleiro do país.

\section{Marco analítico: internacionalização de aglomerações produtivas especializadas}

O estudo inspira-se no debate sobre a importância da aglomeração espacial e das interações densas e positivas para o desempenho de setores e empresas, particularmente PMEs. O marco refere-se, em primeiro lugar, ao tema da internacionalização das aglomerações produtivas especializadas com base, mas não só, nas exportações. O referido debate ganhou vulto a reboque das mudanças, registradas nas últimas décadas em diferentes países, na forma de produzir potencializando o envolvimento de PMEs na dinâmica industrial e no comércio internacional - e na atuação do Estado - estimulando iniciativas de promoção em escala local-regional quase sempre em meio à forte e decisiva interlocução entre as esferas pública e privada e envolvendo distintos níveis de intervenção governamental. Com efeito, em vários casos, a internacionalização das atividades industriais, particularmente no tocante às PMEs, "conta com uma ativa política pública (...), juntamente com o amparo de uma vasta gama de suportes (...) externos de origem tanto pública quanto privada" (Quintar et al. 1993: 46).

Interessa aqui principalmente a problemática das medidas de política em escala de aglomeração. Repleta de experiências, a literatura internacional mostra que as iniciativas costumam representar cruzamento de ações (sobre inovação, competitividade, exportação) que se enfeixam no apoio ao desenvolvimento local-regional. A base é a percepção de que as políticas dirigidas às aglomerações favorecem a atuação de setores e empresas, notadamente PMEs, perante os desafios e incertezas da atualidade e, consequentemente, promovem o desenvolvimento nos territórios implicados. Mas para tanto é preciso, segundo a literatura, que se alcance localmente nível de interações cooperativas entre empresas e envolvendo instituições, capaz de possibilitar o enfrentamento conjunto das adversidades, agregando às externalidades presentes nas aglomerações o caráter de "eficiência coletiva" (Schmitz 1995). Assim, como relatado por Nadvi \& Schmitz (1997), as tentativas de melhora da performance exportadora em nível local têm englobado a organização de grupos de empresas em torno de programas comuns de incremento coletivo da qualidade e competitividade, o descortinamento de novos mercados externos, através de missões empresariais e de participação em feiras/mostras, e a regulação da qualidade dos produtos exportados. 
O olhar aqui lançado ao papel do PROMÓVEL no aglomerado moveleiro de São Bento do Sul é orientado por esse debate. É verdade que tal programa possui corte, antes de tudo, setorial, além de se inserir numa ampla trama de instrumentos de internacionalização voltados às empresas de menor porte (Szapiro \& Andrade 2002). Contudo, haja vista que o essencial da produção de móveis no país ocorre em aglomerações (como se falará posteriormente), é legítimo considerar que a problemática das aglomerações produtivas especializadas, particularmente no tocante à internacionalização, permeia o tema deste artigo.

\section{Produção de móveis no Brasil e na área de São Bento do Sul: o quadro recente}

As últimas décadas registraram mudanças na indústria moveleira em escala mundial. Kaplinsky et al. (2003) destacam a disseminação do uso de maquinário automatizado, a introdução de técnicas modernas de gestão empresarial, o surgimento de novos insumos e matérias-primas, despontando os painéis de madeira (como o Medium Density Fiberboard - MDF) e a multiplicação de produtores importantes. Embora o grosso da produção mundial se concentre num punhado de economias mais industrializadas, países como México e, sobretudo, China galgaram posições como exportadores. Mas também o Brasil exibiu desenvoltura.

\subsection{A indústria moveleira no Brasil}

Em 2005, o Brasil participou da produção mundial e das exportações totais de móveis com, pela ordem, 2,4\% e 1,2\%. Esses níveis não permitem considerá-lo um agente de primeira linha, mas suas vendas externas cresceram rapidamente nos últimos anos. Os móveis de madeira para dormitórios são maioria nas exportações, e os Estados Unidos, alguns países europeus (França, Reino Unido, Alemanha) e a Argentina são os destinos principais (Rosa et al. 2007). A produção concentra-se nos estados de São Paulo, Minas Gerais e na totalidade dos estados sulinos que juntos abrigam mais de $3 / 4$ dos estabelecimentos e mais de $80 \%$ dos empregos (Tabela 1). Ainda mais concentrado é o desempenho exportador. 
GUIMARÃES,P. \& LINS,H. Promovendo exportações de móveis: aspectos da implementação ...

TABELA 1 - DISTRIBUIÇÃO ESTADUAL DA INDÚSTRIA DE MÓVEIS NO BRASIL: 2005

\begin{tabular}{lcccc}
\hline \multirow{2}{*}{ Estados } & \multicolumn{2}{c}{ Estabelecimentos } & \multicolumn{2}{c}{ Empregos } \\
\cline { 2 - 5 } & $\mathrm{N}^{\mathrm{O}}$ & $\%$ & $\mathrm{~N}^{\mathrm{O}}$ & $\%$ \\
\hline São Paulo & 3.645 & 22,8 & 45.041 & 23,4 \\
Rio Grande do & 2.446 & 15,3 & 30.593 & 15,9 \\
Sul & & & & \\
Minas Gerais & 2.129 & 13,3 & 23.926 & 12,4 \\
Paraná & 2.125 & 13,3 & 28.176 & 14,6 \\
Santa Catarina & 2.019 & 12,6 & 30.215 & 15,7 \\
Rio de Janeiro & 570 & 3,6 & 5.230 & 2,7 \\
Goiás & 383 & 2,4 & 3.033 & 1,6 \\
Bahia & 379 & 2,4 & 4.801 & 2,5 \\
Espírito Santo & 325 & 2,0 & 5.080 & 2,6 \\
Ceará & 307 & 1,9 & 3.759 & 1,9 \\
Demais estados & 1.641 & 10,4 & 12.800 & 6,7 \\
Total & 15.969 & 100 & 192.654 & 100 \\
\hline
\end{tabular}

Fonte: RAIS/2005. Obs.: Os dados correspondem à soma das seguintes classes de atividades da CLAS CNAE 95: Classe 36110-Fabricação de móveis com predominância de madeira; Classe 36129-Fabricação de móveis com predominância de metal; Classe 36137-Fabricação de móveis de outros materiais.

A Região Sul tem inequívoca liderança, oscilando entre $75 \%$ e quase $90 \%$ das vendas externas nacionais (Tabela 2). Mas a performance é heterogênea no interior da região: Santa Catarina lidera amplamente, com receitas de exportação que ultrapassam a metade do valor exportado nacionalmente em alguns anos.

A tabela 2 mostra um significativo aumento das exportações no período recente, com uma pequena inflexão em 2006. Entre as razões da expansão estiveram os problemas enfrentados pelo Leste Europeu, um exportador tradicional, que favoreceram a presença brasileira em mercados como os Estados Unidos e países da Europa Ocidental. Assim, se o Brasil ingressou no mercado internacional de móveis já nos anos 70 , foi só mais recentemente que sua posição se consolidou. Tiveram importância 
GUIMARÃES,P. \& LINS,H. Promovendo exportações de móveis: aspectos da implementação ...

TABELA 2 - A REGIÃO SUL NAS EXPORTAÇÕES BRASILEIRAS DE MÓVEIS 1996-2006 (US\$ MILHÕES FOB)

\begin{tabular}{lccccccccc}
\hline & & \multicolumn{2}{c}{$\begin{array}{c}\text { Santa } \\
\text { Catarina }\end{array}$} & \multicolumn{2}{c}{$\begin{array}{c}\text { Rio Grande } \\
\text { do Sul }\end{array}$} & \multicolumn{2}{c}{ Paraná } & \multicolumn{2}{c}{ Região Sul } \\
\cline { 3 - 10 } & Brasil & Valor & $\%$ & Valor & $\%$ & Valor & $\%$ & Valor & $\%$ \\
\hline 1996 & 331,0 & 176,9 & 53,4 & 86,0 & 26,0 & 27,8 & 8,4 & 290,7 & 87,8 \\
1997 & 368,4 & 193,3 & 52,5 & 92,0 & 25,0 & 27,3 & 7,4 & 312,6 & 84,8 \\
1998 & 345,2 & 163,9 & 47,5 & 100,7 & 29,2 & 22,6 & 6,5 & 287,2 & 83,2 \\
1999 & 390,6 & 195,9 & 50,1 & 117,7 & 30,1 & 31,5 & 8,1 & 345,1 & 88,3 \\
2000 & 493,9 & 229,0 & 46,4 & 156,8 & 31,7 & 45,9 & 9,3 & 431,7 & 87,4 \\
2001 & 486,1 & 228,2 & 46,9 & 148,3 & 30,5 & 42,4 & 8,7 & 418,9 & 86,2 \\
2002 & 542,7 & 288,8 & 53,2 & 143,6 & 26,5 & 43,8 & 8,1 & 476,2 & 87,7 \\
2003 & 676,5 & 337,5 & 49,9 & 180,5 & 26,7 & 60,3 & 8,9 & 578,3 & 85,5 \\
2004 & 961,5 & 436,3 & 45,4 & 276,2 & 28,7 & 91,8 & 9,5 & 804,3 & 83,6 \\
2005 & $1.013,2$ & 443,5 & 43,8 & 270,3 & 26,7 & 91,8 & 9,1 & 805,6 & 79,5 \\
2006 & 967,8 & 370,1 & 38,2 & 267,1 & 27,6 & 105,2 & 10,9 & 742,4 & 76,7 \\
\hline
\end{tabular}

Fonte: ALICE-Web/SECEX/MDIC < aliceweb.desenvolvimento.gov.br> . Obs.: Os dados referemse à soma das seguintes posições da Classificação das Mercadorias na Nomenclatura Comum do Mercosul: "94.01 - Assentos (exceto os da posição 94.02), mesmo transformáveis em camas, e suas partes", subtraídos os dados sobre assentos usados em veículos aéreos e automóveis; "94.02 - Mobiliário para medicina, cirurgia, odontologia ou veterinária (...); cadeiras para salões de cabeleireiro e semelhantes (...); suas partes"; "94.03 - Outros móveis e suas partes".

a abertura comercial da década passada, que impulsionou a modernização tecnológica e as mudanças na gestão empresarial, decisivas para incrementos em qualidade e produtividade e para avanços em competitividade.

Todavia, apesar da modernização, a indústria moveleira do Brasil ainda apresenta carências quando comparada ao padrão internacional, como em padronização (Valença et al. 2002). Também a defasagem tecnológica referente ao design, em face dos países que lideram o setor (como a Itália), é algo problemático. Desse modo, embora as vendas externas brasileiras chamem a atenção, o "modelo de exportação" das empresas geralmente se traduz em serviços para terceirização produtiva internacional: os produtos, o design e os requisitos de produção e negociação são definidos pelos clientes estrangeiros. Isso reflete problemas estru- 
turais que travam a expansão do setor, sobressaindo, além da defasagem tecnológica e a falta de design próprio, uma escassa difusão de novas matérias-primas, limitações na normalização técnica, grande informalidade e marcada verticalização produtiva.

Além de concentrada em alguns estados, a produção moveleira ocorre num certo número de aglomerados (Quadro 1). Os aglomerados paulistas, com maior realce para Votuporanga e Mirassol, têm como foco o mercado interno, prevalecendo os móveis retilíneos seriados; na Grande São Paulo destacam-se os móveis para escritório. Uma volumosa produção é observada em Bento Gonçalves (RS), o segundo no rank nacional dos exportadores. Dessa área costumam sair móveis retilíneos seriados (de madeira aglomerada, chapa dura, MDF) para o mercado interno e móveis de pínus para o exterior. Dentre os aglomerados menos expressivos estão os do Paraná e de Minas Gerais. Arapongas, no primeiro, realiza cerca de $7 \%$ das exportações brasileiras, fabricando sobretudo móveis residenciais populares. Em Minas Gerais trata-se, no essencial, de móveis residenciais de madeira e aço destinados ao mercado interno.

O carro-chefe das exportações brasileiras de móveis é, todavia, o aglomerado de São Bento do Sul, em Santa Catarina, onde são fabricados móveis de madeira.

QUADRO 1- PRINCIPAIS AGLOMERADOS MOVELEIROS NO BRASIL

\begin{tabular}{|c|c|c|c|}
\hline Região & Estado & Aglomerado & Produtos principais \\
\hline \multirow{6}{*}{ Sudeste } & $\begin{array}{l}\text { Espírito } \\
\text { Santo }\end{array}$ & $\begin{array}{l}\text { Linhares e } \\
\text { Colatina }\end{array}$ & Móveis retilínios (dormitórios, salas) \\
\hline & \multirow{2}{*}{$\begin{array}{l}\text { Minas } \\
\text { Gerais }\end{array}$} & Ubá & Cadeiras, dormitórios, salas, estantes \\
\hline & & Bom Despacho & Cadeiras, dormitórios, salas, estantes \\
\hline & \multirow{3}{*}{$\begin{array}{l}\text { São } \\
\text { Paulo }\end{array}$} & Votuporanga & Cadeiras, armários, estantes, mesas, dormit., estofad. \\
\hline & & Mirassol & Cadeiras, salas, dormitórios e estantes \\
\hline & & Tupã & Mesas, racks, estantes e cômodas \\
\hline \multirow{4}{*}{ Sul } & Paraná & Arapongas & Móveis retilíneos, estofados de escritório e tubulares \\
\hline & \multirow{2}{*}{$\begin{array}{c}\text { Rio } \\
\text { Grande } \\
\text { do Sul }\end{array}$} & Bento Gonçalves & Móveis retilíneos e metálicos (tubulares) \\
\hline & & Lagoa Vermelha & Dormitórios, salas, estantes e estofados \\
\hline & $\begin{array}{c}\text { Santa } \\
\text { Catarina }\end{array}$ & $\begin{array}{c}\text { São Bento do } \\
\text { Sul e Rio } \\
\text { Negrinho }\end{array}$ & $\begin{array}{c}\text { Salas, estantes, cozinhas e dormitórios (de pínus) para } \\
\text { exportação }\end{array}$ \\
\hline
\end{tabular}

Fonte: Rosa et al. (2007) 
GUIMARÃES,P. \& LINS,H. Promovendo exportações de móveis: aspectos da implementação ...

\subsection{O aglomerado moveleiro de São Bento do Sul}

O aglomerado moveleiro de São Bento do Sul situa-se no Planalto Norte de Santa Catarina e abrange os municípios de São Bento do Sul, Rio Negrinho e Campo Alegre, distando $259 \mathrm{~km}$ de Florianópolis, 93 km de Curitiba e $68 \mathrm{~km}$ de Joinville. A população da área se aproximava de

TABELA 3 - AGLOMERADO MOVELEIRO DE SÃO BENTO DO SUL: ESTABELECIMENTOS E EMPREGOS EM 2005

\begin{tabular}{lcccc}
\hline & \multicolumn{2}{c}{ Indústria moveleira } & \multicolumn{2}{c}{$\begin{array}{c}\text { Indústria de } \\
\text { transformação }\end{array}$} \\
\cline { 2 - 5 } Unidade espacial de referência & Estabelecim. & Empregos & Estabelecim. & Empregos \\
\hline Município de Campo Alegre & 28 & 1.005 & 76 & 1.365 \\
Município de Rio Negrinho & 118 & 3.082 & 265 & 7.352 \\
Município de São Bento do Sul & 187 & 7.354 & 459 & 14.136 \\
Sub Total (aglomerado) & 333 & 11.441 & 800 & 22.853 \\
Santa Catarina & 2.019 & 30.215 & 25.533 & 478.002 \\
\hline
\end{tabular}

Fonte: RAIS/2005. Obs.: Os dados sobre a indústria moveleira correspondem à soma das seguintes classes de atividades da CLAS CNAE 95: Classe 36110-Fabricação de móveis com predominância de madeira; Classe 36129-Fabricação de móveis com predominância de metal; Classe 36137-Fabricação de móveis de outros materiais.

130 mil no Censo de 200o, mais da metade no primeiro município. Pelos dados da RAIS, 333 estabelecimentos moveleiros faziam trabalhar 11.441 empregados em 2005 (Tabela 3), São Bento do Sul abrigando mais da metade das unidades produtivas e quase $2 / 3$ dos empregos, seguido por Rio Negrinho, com, pela ordem, 35\% e $27 \%$.

É indicativo da importância desse setor na área que, em 2005, os vinculados estabelecimentos e empregos representassem $42 \%$ e $50 \%$, respectivamente, dos totais da indústria de transformação, e que a participação do setor moveleiro nas exportações totais seja muito elevada (Figura 1), o que é o caso particularmente de São Bento do Sul. Tudo isso tem atraído vários pesquisadores, que descrevem e analisam o desempenho produtivo e exportador do aglomerado por diferentes ângulos, como ilustrado pelos estudos de Bercovich (1993), Denk (2000), Campos \& Geremia (2004) e Seabra \& de Paula \& Formaggi (2005).

A trajetória moveleira local remonta à década de 30, quando surgiram pequenas marcenarias de produção artesanal após a chegada de imigrantes europeus com conhecimento técnico e experiência. De uma 
produção de "fundo de quintal", passou-se às pequenas oficinas e depois à escala da manufatura, uma progressão que representou a busca de alternativas em face do declínio dos negócios ligados à erva-mate, centrais na área no início do século XX (Kaesemodel 1990). Até o final dos anos 40 o crescimento foi tímido, mas após a Segunda Guerra Mundial multiplicaram-se as empresas, sendo os artefatos de madeira das pequenas marcenarias substituídos pela produção de móveis, em contexto de forte expansão do mercado interno. Tiveram influência nesse percurso a modernização tecnológica, pela introdução de novas máquinas, e o aprimoramento da mão-de-obra.

FIGURA 1 - EXPORTAÇÕES TOTAIS E DE MÓVEIS NO AGLOMERADO MOVELEIRO DE SÃO BENTO DO SUL: 1995-2004 (US\$ MILHÕES)

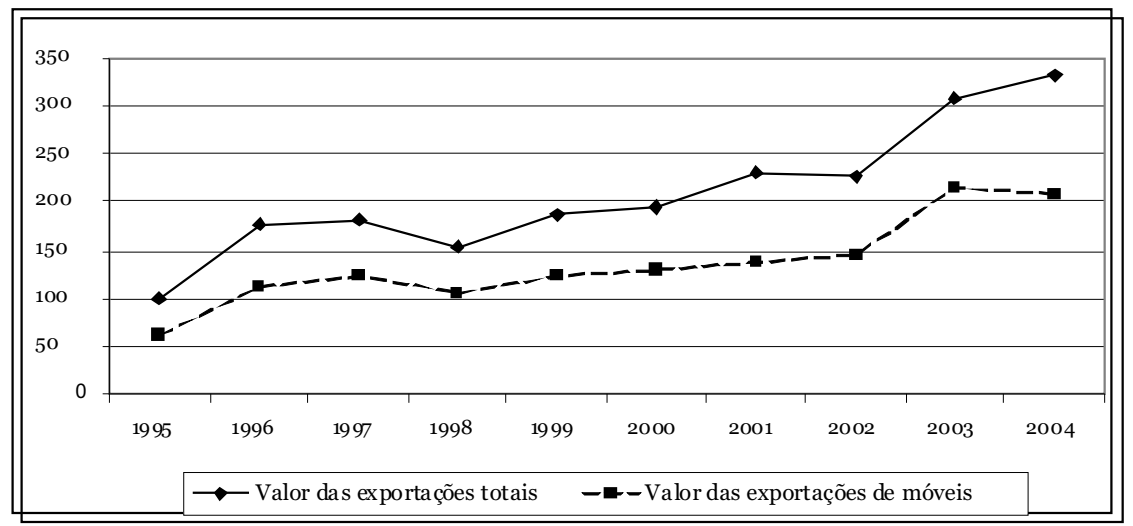

Fonte: Elaboração dos autores com base em dados do Grupo Ecomex/Assessoria Internacional/ Unesc (Extraídos da DIEF/Secretaria da Fazenda do Estado de Santa Catarina: 1995-2004).

O caminho trilhado modelou um importante tecido institucional, ao lado das entidades de representação e coordenação. A Fundação de Ensino, Tecnologia e Pesquisa (FETEP), criada em 1975 para prestar serviços e promover as inovações, angariou destaque, o mesmo ocorrendo com o Serviço Nacional de Aprendizagem Industrial (SENAI), também instalado na década de 70. No final daquela década, foi criado o Centro Tecnológico do Mobiliário (CTM), para atividades em tecnologia e em ensino e pesquisa. Outras instituições são a Universidade do Estado de Santa Catarina (UDESC) e a Universidade do Contestado (UNC), que atendem à necessidade de capacitação da mão-de-obra, e também o Serviço de Apoio às Micro e Pequenas Empresas de Santa Catarina (SEBRAE-SC). A UDESC iniciou suas atividades em $1994 \mathrm{com}$ a oferta de curso superior em Tecnologia Mecânica - Modalidade Produção Industrial de Móveis, 
fruto de parceria com instituições locais. A UNC criou em Rio Negrinho, em 2000, curso de Tecnólogo em Design Moveleiro, objetivando capacitar mão-de-obra para desenvolver design próprio. O melhor nível de vínculos instituições-empresas, segundo estudo do Banco Regional de Desenvolvimento do Extremo Sul (Análise... 2006), é o que envolve o SEBRAE-SC, de atuação estratégica na área porque a grande maioria das empresas é de porte micro ou pequeno, justamente os segmentos alvos dessa instituição.

Nos anos 70, surgiram os primeiros grupos empresariais do setor (Rudnick e Artefama) e, nos 80, mudanças importantes ocorreram nas empresas moveleiras. Perante a retração do mercado interno, intensificou-se o processo de alteração na matéria-prima (consolidando-se o pínus), uma iniciativa impulsionada pela escassez da matéria-prima tradicional (pinho, imbuia). Também se ampliou a busca de espaço no mercado internacional, implicando renovação de processos e meios de produção e mudanças nos móveis produzidos, que passaram do tipo colonial (móveis torneados) para formas mais retas. O aprendizado nessa direção derivou de literatura técnica e de cursos ofertados por FETEP e SENAI, mas também foram importantes os contatos com centros consumidores e os agentes de exportação, em evidência a partir dos anos 80 .

A partir de 1990 ocorreu uma nova fase de modernização tecnológica. Esta mostrou-se vinculada ao crescimento das exportações, impelido pela já referida crise na Europa do Leste, que permitiu ao aglomerado ocupar novos espaços no mercado internacional. O expressivo aumento das vendas externas nos últimos anos, sobretudo no período 20002005 (conforme indicado na tabela 2 e na figura 1), insere-se nesse processo. Os principais destinos dessas exportações são os Estados Unidos, que compram $44 \%$ do total, seguidos por França (18\%), Alemanha (7\%), Holanda (6\%), Reino Unido (5\%) e Espanha (5\%).

Assinale-se que a redução da receita das exportações moveleiras entre 2005 e 2006, de mais de US\$ 70 milhões em toda Santa Catarina (como visto na tabela 2), deve-se, sobretudo, à presente questão cambial. Essa diminuição em nível estadual mostra-se influenciada, na sua maior parte, pela "quebra" de $22 \%$ nos resultados do aglomerado de São Bento do Sul, declínio este que espelha principalmente a situação do principal município da área (Tabela 4). De outra parte, de 2002 em diante, houve uma baixa da participação catarinense nos valores exportados pelo país, pari passu à perda de representatividade da Região Sul como um todo.

Valença et al. (2002) assinalam que esse aglomerado usufrui de vantagens como mão-de-obra especializada, acesso a matéria-prima e um certo nível de atualização tecnológica. Porém ele também amarga fragi- 
lidades, entre as quais uma escassa associatividade, a informalidade, grande dependência das variações cambiais, falta de design próprio e distanciamento do cliente final. Merece realce a forte presença de estruturas verticalizadas, representando entrave ao crescimento, como indica Denk (2000). Além disso, apesar da grande concentração de fornecedores diversos, as interações locais são geralmente rarefeitas, sem transcender a troca de informações sobre desempenho de produtos ou matéria-prima. A cooperação entre empresas é, de fato, baixa, existindo pouca inclinação nesse sentido.

TABELA 4 - PARTICIPAÇÃO DAS EXPORTAÇÕES MOVELEIRAS NO AGLOMERADO MOVELEIRO DE SÃO BENTO DO SUL: 2004-2006 (US\$ MILHÕES)

\begin{tabular}{llccc}
\hline Locais & Exportações & $\mathbf{2 0 0 4}$ & $\mathbf{2 0 0 5}$ & $\mathbf{2 0 0 6}$ \\
\hline \multirow{2}{*}{ São Bento do Sul } & Exportações totais (A) & 259,88 & 261,13 & 202,15 \\
& Exportações moveleiras (B) & 206,44 & 215,95 & 152,29 \\
& B:A*10o & 79,4 & 82,7 & 75,3 \\
\hline \multirow{2}{*}{ Rio Negrinho } & Exportações totais (A) & 91,81 & 95,91 & 107,28 \\
& Exportações moveleiras (B) & 42,85 & 48,2 & 42,26 \\
& B:A*10o & 46,7 & 50,2 & 39,4 \\
\hline \multirow{2}{*}{ Campo Alegre } & Exportações totais (A) & 19,87 & 20,79 & 27,94 \\
& Exportações moveleiras (B) & 18,05 & 20,43 & 27,36 \\
& B:A*10o & 90,8 & 98,3 & 97,9 \\
\hline \multirow{2}{*}{ Aglomerado } & Exportações totais (A) & 371,56 & 377,83 & 337,37 \\
& Exportações moveleiras (B) & 267,34 & 284,58 & 221,91 \\
& B:A*10o & 71,9 & 75,3 & 65,8 \\
\hline
\end{tabular}

Fonte: Elaborado pelos autores com dados da Balança Comercial Brasileira por Município, disponíveis na Secretaria de Comércio Exterior, do Ministério do Desenvolvimento, Indústria e Comércio Exterior, obtidos em <www.desenvolvimento.gov.br/sitio/secex/>

Outro problema é a forma de inserção internacional. As empresas locais têm cultura exportadora, mas as vendas externas dependem de agentes de exportação. Denk (op. cit.) estimou que $56 \%$ de todas as vendas locais ocorriam por meio desses agentes, $25 \%$ dependiam de representantes comerciais no Brasil, $7 \%$ aconteciam de forma direta, $5 \%$ envolviam representantes comerciais no exterior e $4 \%$ e $3 \%$ diziam respeito, pela ordem, a lojas e a outras formas de comercialização. O papel desses agentes é intermediar a comercialização local no exterior, recebendo e repassando as informações tecnoprodutivas originadas dos clientes, incluindo o design e acompanhando o desenvolvimento, a fabricação e 
os testes de qualidade, além de negociar as condições da operação comercial e da logística. Note-se que os vínculos de comercialização acabam resultando de uma espécie de leilão, em que, após o recebimento dos pedidos estrangeiros, os agentes de exportação distribuem a produção entre os fabricantes levando em conta a capacidade destes em termos de qualidade e os preços praticados. O preço é elemento determinante na escolha, e o fato de os compradores terem fornecedores em diversos países - são compradores globais especializados, pela classificação de Kaplinsky et al. (2003) - torna a situação dos fabricantes subordinada à comparação dos preços locais com os preços de outros ambientes produtores. A rápida ascensão da China no mercado mundial é, assim, fonte de inquietação.

A falta de design próprio é uma importante deficiência. São os compradores que, como assinalado, desenvolvem o design, repassando-o às empresas. Assim, estas ostentam um papel determinado, participando de cadeia mundial em que os detentores dos ativos mais importantes, como marca, know-how e canais de comercialização/distribuição, são os grandes clientes. Na estrutura de governança que caracteriza essas relações, as atividades de maior valor agregado são, desse modo, prerrogativa dos compradores, ficando as de menor valor para os produtores. Daí que, na área de São Bento do Sul, a "pauta de exportação das empresas é pouco diversificada e se concentra em produtos de pínus com baixo e médio valor agregado, como dormitórios, salas de jantar e móveis de escritório" (Análise... 2006:153).

Entretanto, não se pode dizer que a participação local nesse tipo de vínculo externo não outorgue benefícios. $\mathrm{O}$ acesso às informações sobre procedimentos produtivos, com reflexos na gestão, melhorando a qualidade e a produtividade, constitui ilustração. Seja como for, a inserção internacional mostra-se subordinada, talvez inibindo o pleno uso das potencialidades locais, pois a possibilidade de upgrading industrial se resume aos processos produtivos e aos produtos. Upgrading funcional, levando ao desempenho de funções superiores (design, marketing) nas cadeias de valor, tende a ser inibido pelos grandes clientes internacionais (Humphrey \& Schmitz 2002). Ora, em tais situações, os mecanismos de promoção das exportações em melhores bases costumam se mostrar estratégicos. O Programa Brasileiro de Incremento às Exportações de Móveis (PROMÓVEL) foi idealizado nessa perspectiva.

\section{O Programa Brasileiro de Incremento às Exportaccões de Móveis (PROMÓEL)}

Concebido para promover as exportações moveleiras, o PROMÓVEL resultou de iniciativa conjunta entre a Associação Brasileira das Indús- 
trias do Mobiliário (ABIMÓVEL) e órgãos públicos como o Ministério do Desenvolvimento, Indústria e Comércio Exterior (MDIC), a Financiadora de Estudos e Projetos (FINEP), o Conselho Nacional de Pesquisa e Desenvolvimento (CNPq) e a Agência de Promoção de Exportações (APEX). Criado em 1998, com 16 projetos, esse programa objetivava incrementar as exportações com agregação de valor aos móveis brasileiros. Eram duas as orientações básicas de trabalho: "estruturar as empresas no sentido de capacitá-las para a exportação de móveis" (Manual 1998:4) e "aumentar as exportações de móveis brasileiros para o mercado norte-americano" (Ibid). Contemplava-se a geração de 10 mil novos empregos, a inserção de 300 empresas no mercado externo e o alcance de 13,5 mil empresas instaladas em todo o Brasil. Nas exportações, o objetivo era atingir montantes anuais de US\$ 2,5 bilhões, mediante reestruturação empresarial que permitisse avanços em competitividade e o fortalecimento de entidades de representação, que teriam melhoradas as suas funções.

A coordenação do programa ficou com a ABIMÓVEL, auxiliada por um grupo gestor cuja principal função era "promover o alinhamento estratégico de todas as ações a serem deflagradas. Ele seria também responsável pelo controle de qualidade do programa" (Manual op cit.:5). Representantes da diretoria da ABIMÓVEL, da Associação das Indústrias de Móveis do Estado do Rio Grande do Sul, do Sindicato das Indústrias do Mobiliário e Artefatos de Madeira no Estado de Minas Gerais e do Centro Tecnológico do Mobiliário comporiam esse grupo gestor. Os recursos viriam das instituições envolvidas e das empresas participantes: na APEX seriam liberados R\$ 5 milhões durante três anos; R\$ 2,5 milhões corresponderiam a contribuições mensais de fornecedores; e R\$ 2,5 milhões originar-se-iam das empresas, que pagariam mensalmente, cada uma, R\$ 100,00 durante os 36 meses do programa.

Entidades executoras em cada região do país seriam responsáveis pela implementação das ações junto aos fabricantes, com atividades que abrangeriam contratação de serviços e controle de execução das despesas. A definição sobre o envolvimento das instituições ocorreu em novembro de 1998, e a implantação do programa foi iniciada em março de 1999, perdurando até dezembro de 2002. Várias empresas em distintos estados brasileiros foram envolvidas, pois se abria a possibilidade de participação de entidades de representação/coordenação e de fabricantes em diferentes localizações no país. Segundo Pamplona (2001), a participação empresarial teve o perfil indicado na tabela 5. A maioria das empresas se fez presente em grupo, sendo que Paraná, Rio Grande do Sul e Santa Catarina mostraram os maiores números. As empresas eram tanto de grande porte, como médias, pequenas e micro, as 
GUIMARÃES,P. \& LINS,H. Promovendo exportações de móveis: aspectos da implementação ...

TABELA 5 - PARTICIPAÇÃO EMPRESARIAL NO PROMÓVEL POR ESTADO

\begin{tabular}{lccc}
\hline \multirow{2}{*}{ Estado } & \multicolumn{3}{c}{ Empresas Participantes } \\
\cline { 2 - 4 } & $\begin{array}{c}\text { Empresas em } \\
\text { Grupo }\end{array}$ & Empresas Avulsas & Total \\
\hline Paraná & 86 & 42 & 128 \\
Rio Grande & 99 & 12 & 111 \\
do Sul & & & \\
Santa & 61 & 34 & 95 \\
Catarina & 35 & 32 & 67 \\
São Paulo & 50 & 0 & 50 \\
Espírito Santo & 36 & 13 & 49 \\
Minas Gerais & 17 & 0 & 17 \\
Bahia & 10 & 0 & 10 \\
Ceará & 10 & 0 & 10 \\
Distrito & 10 & 0 & 10 \\
Federal & 9 & 0 & 9 \\
Roraima & 9 & 0 & 9 \\
Maranhão & 0 & 2 & 2 \\
Pernambuco & 0 & 1 & 1 \\
Rio de Janeiro & 432 & 136 & 568 \\
Rio Grande & & & \\
do Norte & Total & & 0
\end{tabular}

Fonte: Pamplona (2001).

microempresas e as médias e pequenas empresas participando normalmente em grupo, e as poucas grandes preferindo a individualidade.

Os 16 projetos do programa foram agrupados em 3 blocos, apresentados no quadro 2. Os projetos de capacitação gerencial, adequação de plantas fabris, ISO 9000, ISO 14000 e obtenção de know-how implicaram a realização de diversos cursos, seminários e treinamentos, com muitos participantes e muitas horas de trabalho. Os projetos sobre exposição internacional abrangeram esforços de marketing por meio de reportagens, artigos e entrevistas em canais de divulgação estrangeiros, na mídia impressa (revistas como Furniture Today, Furnishing, Möbelmarket) e audiovisual, e iniciativas de participação em feiras/ mostras importantes (como em Birmingham, Inglaterra; Dubai, Emirados Árabes; Tóquio, Japão; Tupelo, Estados Unidos). A busca de conhecimento e prospeç̧ão do mercado estadunidense envolveu pesquisa de mercado, dezenas de workshops em aglomerados moveleiros e divulgação de livro sobre o assunto. Este último tipo de ação - lançamento e distribuição de publicações - desdobrou-se em preparação de numerosos volumes sobre temas de interesse da indústria, incluindo 
comércio exterior. Sobre design, registre-se a criação de núcleos de desenvolvimento de atividades correspondentes em vários aglomerados, em parceria com o CNPq e o Programa Brasileiro de Design, do Ministério do Desenvolvimento, Indústria e Comércio Exterior (Programa 2002).

Como se deu a experiência do PROMÓVEL no aglomerado de São Bento do Sul? Formar uma idéia a respeito disso, com base, principalmente, em depoimentos de empresas locais que participaram da iniciativa, é o que se pretende no restante do artigo.

\section{O PROMÓVEL no aglomerado moveleiro de São Bento do Sul}

A base desta seção é formada pelo conjunto de entrevistas realizadas em empresas e pelas informações obtidas em instituições da área, conforme indicado na introdução.

\subsection{Providências e movimentos iniciais}

O PROMÓVEL começou a ser implantado no aglomerado de São Bento do Sul em março de 1999. Os principais protagonistas foram o Sindicato das Indústrias da Construção e do Mobiliário de São Bento do Sul (SINDUSMOBIL) e o Sindicato das Indústrias da Construção e do Mobiliário de Rio Negrinho (SINDIRNI). A motivação básica dizia respeito à incrustada possibilidade de diversificar os mercados de exportação, pois

QUADRO 2 - PROJETOS INTEGRANTES DO PROMÓVEL

\begin{tabular}{|l|l|}
\hline Projeto & Conteúdo \\
\hline Bloco "Negócios" & $\begin{array}{l}\text { Criação de consórcios de micro e pequenas } \\
\text { empresas e consórcios de produtores de } \\
\text { partes e peças. }\end{array}$ \\
\hline Exposições internacionais & $\begin{array}{l}\text { Promoção da participação conjunta das } \\
\text { empresas em exposiçôes no exterior. }\end{array}$ \\
\hline $\begin{array}{l}\text { Pontos de negócios avançados } \\
\text { no exterior }\end{array}$ & $\begin{array}{l}\text { Definição de estratégias de inserção das } \\
\text { empresas em mercados externos com base } \\
\text { em estudos de mercado. }\end{array}$ \\
\hline Marketing no exterior & $\begin{array}{l}\text { Elaboração de plano de marketing focado } \\
\text { na mídia internacional e direcionada para } \\
\text { feiras e congressos. }\end{array}$ \\
\hline
\end{tabular}




\begin{tabular}{|c|c|}
\hline \multicolumn{2}{|c|}{ Bloco "Cultura Exportadora" } \\
\hline $\begin{array}{l}\text { Estudos de mercados } \\
\text { internacionais }\end{array}$ & $\begin{array}{l}\text { Realização de estudos sobre mercados } \\
\text { nacionais, definição das prioridades e } \\
\text { prospecção por consórcios de exportação. }\end{array}$ \\
\hline $\begin{array}{l}\text { Desenvolvimento de } \\
\text { design }\end{array}$ & $\begin{array}{l}\text { Estímulo à cultura do design e capacitação } \\
\text { das empresas para fazer design de alto } \\
\text { valor. }\end{array}$ \\
\hline Missões empresariais & $\begin{array}{l}\text { Estreitamento de laços entre empresários } \\
\text { brasileiros e estrangeiros mediante visitas } \\
\text { e participações em feiras e rodadas de } \\
\text { negócios. }\end{array}$ \\
\hline Selo verde & $\begin{array}{l}\text { Estabelecimento de condições e } \\
\text { parâmetros para emissã de certificados } \\
\text { de origem da matéria-prima utilizada. }\end{array}$ \\
\hline $\begin{array}{l}\text { Obtenção de know-how } \\
\text { no exterior }\end{array}$ & $\begin{array}{l}\text { Criação de comissões para estágios em } \\
\text { instituições estrangeiras, com posterior } \\
\text { difusã das informaçôes obtidas. }\end{array}$ \\
\hline $\begin{array}{l}\text { Prospecção do mercado } \\
\text { Estadunidense }\end{array}$ & $\begin{array}{l}\text { Identificação das características e } \\
\text { necessidades do mercado estadunidense e } \\
\text { levantamento do respectivo potencial. }\end{array}$ \\
\hline $\begin{array}{l}\text { Produção de normas } \\
\text { técnicas }\end{array}$ & $\begin{array}{l}\text { Criação de comissões de trabalho sobre } \\
\text { normas técnicas, com posterior } \\
\text { distribuição dos resultados entre as } \\
\text { empresas. }\end{array}$ \\
\hline \multicolumn{2}{|l|}{ Bloco "Estruturação" } \\
\hline Capacitação gerencial & $\begin{array}{l}\text { Capacitação gerencial de empresas } \\
\text { exportadoras em cursos modulares } \\
\text { ministrados em diferentes localidades } \\
\text { produtoras. }\end{array}$ \\
\hline $\begin{array}{l}\text { Adequação de plantas } \\
\text { fabris }\end{array}$ & $\begin{array}{l}\text { Treinamento sobre racionalização e } \\
\text { produtividade industrial, focando a } \\
\text { adequação do lay-out e do fluxo de } \\
\text { produção. }\end{array}$ \\
\hline ISO 9000 & $\begin{array}{l}\text { Orientação sobre procedimentos relativos } \\
\text { ao padrão de qualidade internacional e } \\
\text { certificação. }\end{array}$ \\
\hline ISO 14000 & $\begin{array}{l}\text { Sensibilização das empresas sobre a } \\
\text { importância do desenvolvimento } \\
\text { sustentável, até para conquistar mercados }\end{array}$ \\
\hline $\begin{array}{l}\text { Gestão de qualidade e } \\
\text { produtividade }\end{array}$ & $\begin{array}{l}\text { Definição de critérios sobre desempenho e } \\
\text { oferta de instrumentos para avaliar a } \\
\text { gestão da Q\&P. }\end{array}$ \\
\hline
\end{tabular}

Fonte: Pamplona (2001). 
o aglomerado já exibia forte dinamismo exportador. Os sindicatos divulgaram a iniciativa pela distribuição de informativos e as empresas foram convidadas a participar das reuniões de apresentação do programa. Para facilitar o contato e lubrificar a adesão dos empresários, um escritório do PROMÓVEL, abrigando as atividades do grupo gestor, foi criado em São Bento do Sul, nas mesmas dependências do SINDUSMOBIL. Esse grupo era integrado pelo diretor regional da ABIMÓVEL em Santa Catarina e por mais dois funcionários daquela associação, assim como por uma pessoa contratada na própria área, cuja responsabilidade incluía implementar os projetos, estabelecer as metas, com os prazos a cumprir, fazer as prestações de contas, efetuar o controle de qualidade na implementação, estabelecer contatos com clientes no exterior, organizar missões empresariais e fazer reuniões mensais de informação aos empresários sobre o andamento das atividades (Pamplona 2001).

Inicialmente demonstraram interesse 62 empresas, 50 com envolvimento em grupo ( 5 grupos de 10 empresários cada um) e 12 individualmente, segundo informação do SINDIRNI em entrevista. Em Campo Alegre participaram 2 empresas; em Rio Negrinho, 20; em São Bento do Sul, 40 (op cit.). Todavia, após período não superior a seis meses, muitas empresas desistiram, tendo só 35 permanecido e participado efetivamente. Pelas informações dos sindicatos e também de algumas empresas entrevistadas, a principal causa da desistência foi a falta de confiança no projeto e nos seus gestores. Mas houve também outros motivos, ligados a problemas evidenciados logo nos primeiros passos da implementação, como se realçará posteriormente. Cabe assinalar agora, entre os motivos, uma certa pressão dos agentes de exportação, principalmente em empresas menores, influenciando-as contra a participação. Isso incluía tentativas de depreciar o programa aos olhos das empresas: os agentes esforçaram-se em divulgar a idéia de que o PROMÓVEL não tinha razão de ser, que as empresas não precisavam desse instrumento para diversificar os mercados e exportar mais. Esse empenho não era fortuito, pois, se o programa fosse implantado com sucesso, a dependência dos fabricantes exportadores em relação aos agentes de exportação haveria de diminuir. E deve-se também considerar que, no momento da implantação, ocorria um forte crescimento nas vendas externas de móveis. As razões dessa expansão nada tinham a ver com programas de promoção das exportações, e sim - pelo menos em grande medida - com fatores estruturais da economia como um todo, sobretudo a situação do câmbio: a forte desvalorização da moeda brasileira no início de 1999 colocou por terra a postura que se cultivava desde o Plano Real. Segundo agentes locais entrevistados, esse quadro, favorável às vendas externas, produziu desinteresse pelo programa, já que as receitas de exportação só faziam crescer. Assim, pode-se dizer 
que as empresas não se empenharam para que os objetivos propostos para a região fossem atingidos. Os próprios entrevistados admitiram não terem se esforçado para o sucesso.

\subsection{PROMÓVEL em São Bento do Sul: perscrutando os resultados}

\subsubsection{Caracterização das empresas entrevistadas}

Das nove empresas entrevistadas, seis tiveram o primeiro contato com o PROMÓVEL por meio dos sindicatos aos quais se filiam. As outras três indicaram formas distintas de contato: informações da ABIMÓVEL, do consórcio de exportação freqüentado e de outras empresas. Isso sugere a importância do SINDUSMOBIL e do SINDIRNI na divulgação do programa e o seu papel na aproximação das empresas aos projetos. Outro aspecto é que as empresas pesquisadas eram eminentemente exportadoras. Só $23 \%$ vendiam tanto para o mercado interno como para o externo, e, portanto, mais de 3/4 tinham em outros países os destinos da totalidade da produção, o que basta para assinalar o quanto essas empresas dependiam do mercado internacional. Por extensão, haja visto que os vínculos externos dessas empresas implicam fortemente a atuação de agentes de exportação, esses dados indicam que uma parcela esmagadoramente majoritária dos negócios dependiam desse tipo de agente. De fato, em quase todas as vendas externas dessas empresas, a comercialização envolvia essa figura: o percentual de venda direta ao consumidor estrangeiro era, em média, inferior a $5 \%$.

Todas essas empresas já exportavam antes da implementação do PROMÓVEL. A maioria exportava havia mais de cinco anos, uma informação que corrobora a idéia de que é forte a cultura exportadora local. Cabe agregar que, de acordo com o que se captou nas visitas, entre mais ou menos 1999 e 2004 diversas empresas mudaram o mercado para o qual produziam. Empresas que antes fabricavam simultaneamente para os mercados interno e externo passaram a produzir somente para o segundo. $\mathrm{O}$ motivo é que os móveis destinados à exportação tendem a ser diferentes dos orientados ao mercado nacional, exigindo esforço de adequação produtiva que restringe um uso distinto nos processos de fabricação. Daí que a orientação exportadora significou privilégio, quando não exclusividade, do mercado internacional. 


\subsubsection{Projetos implementados}

Dos dezesseis projetos do PROMÓVEL, só dez entraram na implementação do programa na área em foco. Os de maior destaque para as empresas estudadas foram os de gestão da qualidade e produtividade e de missões empresariais. Mas os de estudos sobre mercados internacionais e de produção de normas técnicas para fabricação de móveis também atraíram a atenção (Tabela 6).

TABELA 6 - PROJETOS DO PROMÓVEL NAS EMPRESAS ENTREVISTADAS

\begin{tabular}{lc}
\hline Projetos implantados & $\begin{array}{c}\text { No empresas } \\
\text { participantes }\end{array}$ \\
\hline Programa de gestão de qualidade e produtividade & 5 \\
Missões empresariais & 4 \\
Produção de normas técnicas para a fabricação de móveis & 4 \\
Estudos de mercados internacionais & 3 \\
Adequação de plantas fabris & 3 \\
Aquisição de know-how no exterior & 2 \\
Mostra de móveis brasileiros em exposições internacionais & 1 \\
Capacitação gerencial em exportação & 1 \\
ISO 9ooo & 1 \\
Desenvolvimento de design & \\
\hline
\end{tabular}

Fonte: Elaboração própria com base em pesquisa de campo.

O projeto de gestão da qualidade e produtividade foi implantado em cinco das nove empresas, refletindo o interesse dos fabricantes em aprimoramento com vistas à comercialização no exterior. O projeto de missões empresariais também foi implantado em cinco empresas, denotando a curiosidade dos fabricantes sobre os clientes estrangeiros e o interesse numa certa aproximação a estes, mesmo que as interações comerciais não fossem diretas, mas intermediadas por agentes de exportação. $\mathrm{O}$ interesse de numerosas empresas pelos projetos de normas técnicas para fabricação de móveis e de estudos sobre mercados internacionais é coerente com a maior atenção da empresas aos dois projetos assinalados anteriormente, pela ordem. O de adequação de plantas fabris foi apontado com destaque por sinalizar com chance de reestruturação em empresas que não tinham apoio e suporte para isso; esse projeto 
oportunizou principalmente reformas nas instalações e melhorias no lay-out.

Os projetos foram acompanhados pelos sindicatos da região e também, embora em menor grau, por consultores do PROMÓVEL. Estes últimos eram responsáveis pela coordenação do programa, ficando a execução e o acompanhamento a cargo do SINDUSMOBIL e do SINDIRNI. O acompanhamento implicava manter as empresas informadas sobre as etapas, o cronograma, as reuniões e os cursos. Depois de cumpridas as etapas, o acompanhamento permitia verificar como as atividades tinham ocorrido e avaliar se os processos haviam se desenrolado conforme o esperado. Assinale-se que as informações coletadas nas entrevistas sugerem problemas no acompanhamento: essa tarefa deveria caber amplamente aos sindicatos, mas, entre os fabricantes entrevistados, o SINDUSMOBIL e o SINDIRNI assim procederam só em cinco dos nove casos; ainda mais eloqüente é que numa empresa o "acompanhamento" se deu pelo Pro Notícias, um informativo mensal que comunicava sobre reuniões, cursos, feiras e missões empresariais a serem realizados.

\subsubsection{Os resultados em questão: mais sombras do que}

$O$ aspecto tratado no final da parte anterior ajuda a entender o resultado da pesquisa que, seguramente, mais chama a atenção: o grau de satisfação das empresas em relação aos projetos realizados. Nada menos que $2 / 3$ dos entrevistados declararam-se insatisfeitos e os restantes informaram terem ficado apenas parcialmente satisfeitos. Quer dizer, nenhuma empresa exibiu satisfação plena. A primeira vista, esse resultado é surpreendente. Entretanto, uma observação mais acurada favorece a compreensão.

Um aspecto relaciona-se às exportações, pedra angular do PROMÓVEL em termos gerais. Quando perguntados sobre a expansão dessas vendas no período imediatamente posterior à implementação do programa, os fabricantes responderam unanimemente que o incremento nada tinha a ver com a sua participação nos projetos. No mesmo diapasão, constatou-se que em nenhuma empresa a adesão representou mudança no canal de comercialização no exterior. Todas continuaram a ter como principal instrumento o agente de exportação. Ou seja, o objetivo de lograr uma aproximação com o cliente estrangeiro, contemplando a venda sem intermediação, acabou não sendo alcançado. Ora, sobretudo entre as empresas de médio porte, havia a esperança de que o programa pudesse alterar aquela condição, sendo, portanto, compreensível a frustração instalada. 
Mas essa questão é controversa. À interrogação sobre a melhor forma de comercializar externamente, as empresas deram respostas divergentes. As de pequeno porte e as microempresas preferem contar com agentes de exportação, pois se sentem mais seguras com os serviços destes. Já as empresas de médio porte asseguram que a venda direta ao cliente lhes proporcionaria melhores resultados. Por exemplo, no quadro de atuais dificuldades para exportar, ligado em grande medida à valorização da moeda brasileira, essas empresas muitas vezes fecham o mês com dificuldades financeiras, mas são obrigadas a pagar aos agentes de exportação comissões de 7 a $10 \%$ sobre o total das vendas.

Outro aspecto é que, conforme visto na tabela 6 , só uma empresa aderiu ao projeto sobre design. Isso chama a atenção, pois nenhum dos fabricantes possuía design próprio; apontou-se numa entrevista que se costuma apenas contar com desenhistas que copiam o design de revistas e de e-mails mandados por clientes, por exemplo. Descobriu-se que, em vários casos, as empresas não teriam interesse em desenvolver design, pelo temor de, ao agregar valor aos produtos, perderem os clientes, devido ao aumento dos preços praticados. Preferem, desse modo, receber o design dos compradores e produzir de acordo com as diretrizes destes. Não se pode dizer que isso não se justifica: os compradores internacionais são abastecidos por fabricantes em diversos países e regiões do mundo, e os preços constituem fator determinante na escolha dos fornecedores; o aumento dos preços locais pode fazer os clientes internacionais ampliarem as compras em regiões produtoras mais competitivas. Ainda assim, causa admiração que o projeto envolvendo design tenha atraído tão pouco interesse. O PROMÓVEL acenava com a diversificação dos mercados, com a abertura de outros destinos estrangeiros, além dos tradicionalmente explorados. Nesses novos mercados, entre os quais os Emirados Árabes eram vistos com expectativa, as empresas poderiam tentar inserção com móveis feitos com design próprio.

Em que pese todos os problemas apresentados e as manifestações de insatisfação, a maioria dos entrevistados admitiu ser boa a idéia do programa. A principal dificuldade teria sido a má implementação. Assim, as empresas não deixaram de indicar ganhos. Conforme a tabela 7 , houve destaque para um certo avanço, permitido pelo programa, no conhecimento sobre o mercado externo, devido aos estudos sobre mercados internacionais e às missões empresariais. Alguma melhoria no nível de qualidade dos produtos, fruto do projeto sobre gestão da qualidade e produtividade, e na capacitação gerencial e operacional das empresas foi igualmente apontada, mesmo que em poucas entrevistas. Trata-se de resultados geralmente contemplados nas iniciativas de política voltadas às aglomerações produtivas que priorizam as exportações, como 
acentuado na segunda seção do artigo. O ganho menos indicado vinculou-se ao projeto de aproximação dos fabricantes aos clientes estrangeiros.

TABELA 7 - VANTAGENS DA ADESÃO AO PROMÓVEL PARA AS EMPRESAS

\begin{tabular}{lc}
\hline Tipos de ganhos das empresas & No de empresas \\
\hline Conhecimento do mercado externo & 4 \\
Nenhum ganho & 3 \\
Capacitação gerencial e operacional & 2 \\
Melhoria do nível de qualidade dos produtos & 2 \\
Aproximação com o cliente & 1 \\
\hline
\end{tabular}

Fonte: Elaboração própria com base em pesquisa de campo.

Mas três das nove empresas informaram não terem obtido qualquer ganho com o PROMÓVEL, e, assim, não admira que várias críticas tenham sido efetuadas nas entrevistas. As principais referem-se a problemas na atuação dos gestores do programa, dizendo sobretudo respeito ao que foi diagnosticado como "falta de profissionalismo" e à inadequada consideração das especificidades da área, tradução para, conforme as opiniões, "ausência de estudo prévio sobre a região". A tabela 8 sistematiza as críticas feitas.

TABELA 8 - CRÍTICAS DAS EMPRESAS ENTREVISTADAS AO PROMÓVEL

\begin{tabular}{lc}
\hline Críticas & No de empresas \\
\hline Problemas na atuação dos gestores do programa & 7 \\
Inadequada consideração das especificidades da área & 7 \\
Deficiente seleção dos clientes & 5 \\
Desconsideração das sugestões das empresas participantes & 2 \\
\hline
\end{tabular}

Fonte: Elaboração própria com base em pesquisa de campo.

As empresas destacaram ser preciso um estudo prévio sobre a região, pois, segundo a maioria, a implantação do programa não levou em conta as carências da área. Isso se refletia nos cursos oferecidos e também nos clientes estrangeiros contatados em feiras e missões internacionais. Para os entrevistados, o PROMÓVEL deveria ser aplicado de acordo com a necessidade específica de cada aglomerado, e não de modo 
padronizado, como se tivesse validade no país como um todo. Esse foi um dos mais importantes ensinamentos da pesquisa de campo, é importante sublinhar. Para pouco menos de $60 \%$ dos entrevistados, era essencial que os projetos fossem implementados em sintonia com a "cultura da região”, algo que, na opinião prevalecente, não ocorreu. Isso representa uma grande deficiência em relação a dois aspectos centrais das políticas de promoção vinculadas às aglomerações produtivas, conforme tratado no início do artigo: a interlocução entre as esferas pública e privada, em diferentes níveis, e o caráter cooperativo das interações.

Também recorrente foi a crítica ao que foi percebido como "falta de profissionalismo" dos gestores do PROMÓVEL. Segundo as empresas, estes pareciam não estar interessados em desenvolver o programa.

Chegou-se a dizer que não levaram o trabalho a sério, opinião escorada no fato de, segundo os depoimentos, terem as empresas experimentado a necessidade de "correr atrás" dos gestores para obter informações sobre as etapas. Isso se revelou problemático já nos primeiros meses, e, assim, os empresários se inscreveram, pagaram as mensalidades, mas não vendo a materialização do que havia sido programado, desinteressaram-se, afastando-se em decorrência. Pertence, de certa forma, a esse âmbito a frustração das expectativas sobre os cursos oferecidos pelos consultores do PROMÓVEL: segundo as entrevistas, seu objeto não ia além de aspectos burocráticos das exportações, já conhecidos dos empresários.

Da mesma forma, houve problemas na atração de clientes estrangeiros. Para as empresas, o mercado alvo fora bem selecionado, mas o mesmo não podia ser dito sobre os clientes: os entrevistados disseram que os clientes (ou candidatos a clientes) cuja aproximação foi promovida não interessavam às empresas. Sustentou-se essa opinião com referências à feira Móvel Brasil, realizada em São Bento do Sul até 2003, na qual acontecia o chamado "projeto comprador". Rodadas de negócios ocorriam diariamente, envolvendo clientes que compareciam devido aos contatos dos consultores do programa, mas, na opinião unânime dos entrevistados, esses clientes não estavam interessados em negociar, tanto que geralmente chegavam ao final das reuniões ou nem mesmo as freqüentavam. A percepção é que não se tratava de bons clientes, pois sequer conheciam adequadamente os termos técnicos do setor de móveis. Assim, no que respeita ao "projeto comprador", alguns entrevistados chegaram a afirmar que foram "enganados pelos consultores do PROMÓVEL", não tendo jamais concretizado negócios com os pretensos compradores.

Foi igualmente dura a crítica à não colocação em prática das sugestões das empresas, o que remete aos já mencionados problemas relativos à 
interlocução público-privada e aos vínculos cooperativos. Merece destaque, como exemplo, a recomendação de que os gestores agissem de maneira mais criteriosa na escolha dos clientes estrangeiros a serem trazidos ao Brasil. Isso tem a ver também com o tipo de dificuldade surgida nas rodadas de negócios durante as feiras, algo que exigiria uma confirmação prévia sobre as reais intenções desses clientes. Mostravase também essencial verificar se os móveis que as empresas da área fabricam e costumam exportar atendiam aos interesses dos compradores em potencial.

Nessas interações com agentes internacionais, somaram-se aos problemas vivenciados na própria região aqueles relativos à projeção externa dos fabricantes locais. Grandes dificuldades foram apontadas na participação em feiras internacionais e nas viagens para obtenção de knowhow no exterior. É ilustrativo o depoimento da diretora da área de exportação de uma das empresas pesquisadas em Rio Negrinho. A entrevistada informou que, numa viagem à Itália para obter/ampliar conhecimento em design, não teve acesso, ela e os demais membros da missão, às empresas definidas para as visitas. Motivo: os encontros não haviam sido agendados. Também eloqüente é o fato de terem sido incluídos, no programado curso de design, conteúdos sobre, por exemplo, fabricação artesanal de cortinas e tapetes, sem relação com os interesses dos fabricantes de móveis. O diagnóstico dessa entrevistada foi contundente: tudo fora muito mal organizado pelos gestores do PROMÓVEL.

Essa avaliação corrobora um outro problema apontado nessas viagens, referente aos acompanhantes dos empresários nas missões empresariais. Mostrou-se necessário que, além de atuarem como intérpretes, os acompanhantes também tivessem familiaridade com a indústria moveleira. Razão: para que o tipo de iniciativa em questão tenha sucesso, é preciso que o acompanhante saiba interpretar termos técnicos e, em alguma medida, conheça aspectos da produção de móveis. Segundo as entrevistas, nada parecido foi proporcionado no âmbito do PROMÓVEL.

\section{Considerações finais}

Como se observou, pelo menos junto às empresas pesquisadas, o PROMÓVEL não foi bem sucedido no aglomerado de produção moveleira que mais destaque exportador exibe em escala de país. As principais razões residiram na escassez de motivação e de interesse das empresas e nos problemas de condução no processo de implantação, ambos os pontos representando deficiências em relação a dois aspectos centrais das políticas de promoção vinculadas às aglomerações produtivas: a 
interlocução público-privada e a cooperação entre empresas e implicando instituições. Assim, os bons resultados exportadores registrados nos últimos anos por São Bento do Sul e sua área não guardam relação com esse programa. Esta foi uma opinião unanimemente manifestada pelos agentes entrevistados, e até comunicada com veemência por alguns representantes das empresas visitadas. Contudo, mesmo em face dos percalços enfrentados e das decorrentes frustrações, houve demonstração de interesse num eventual novo envolvimento em esquemas de promoção das atividades de produção e exportação. Ouviu-se nas entrevistas que uma reestruturação daquele programa, com mudanças em nível de grupo gestor e, talvez em primeiro lugar, com o aumento do espaço de participação das empresas, no tocante à concepção - equacionando o grave problema da indicada falta de sintonia entre a estrutura do PROMÓVEL e as reais necessidades específicas da área - e à implementação, haveria certamente de permitir o cumprimento do seu idealizado papel na área de São Bento do Sul.

\section{Referências}

ABIMÓVEL (1998) Manuel do Promóvel. Edição ABIMÓVEL/PROMÓVEL.

ABIMÓVEL (2002) Programa brasileiro de incremento à exportação de móveis - Resenha: dados gerenciais dos resultados alcançados. ABIMÓVEL/PROMÓVEL, s/l, set.

BRDE (2006). Análise da competitividade das principais aglomerações produtivas de móveis da Região Sul do Brasil. Florianópolis: Gerência de Planejamento.

BERCOVICH, Néstor (1993). Análisis de la internacionalización de la industria del mueble de São Bento do Sul (Santa Catarina, Brasil), a la luz de la experiencia de los distritos industriales italianos. Progetto Finalizzato CNR "Il sistema delle politiche e dei servizi reali per la proiezione internazionale del sistema produttivo italiano", Roma, Università di Roma "Tor Vergata".

CAMPOS, R. \& GEREMIA, F. (2004). "Possibilidade de upgrading proporcionado pela inserção do mercado internacional da indústria do mobiliário do Estado de Santa Catarina”. XXIII Simpósio de Gestão da Inovação Tecnológica, Curitiba, NPGT/USP. Anais pp. 380-394 (CD ROM).

DENK, Adelino (2000). Dinâmica competitiva do cluster moveleiro da região de São Bento do Sul-Santa Catarina. Florianópolis: Dissertação de Mestrado, Universidade Federal de Santa Catarina, Programa de Pós-Graduação em Economia.

HUMPHREY, J. \& SCHMITZ, H. (2002). Developing country firms in the World Economy: governance and upgrading in global value chains. INEF Report, Institut für Entwicklung und Frieden der Gernard-Mercator-Universität Duisburg, Heft 61.

KAESEMODEL, Maria (1990). A indústria moveleira em São Bento do Sul-SC. Florianópolis: Dissertação de Mestrado, Universidade Federal de Santa 
GUIMARÃES,P. \& LINS,H. Promovendo exportações de móveis: aspectos da implementação ...

Catarina, Programa de Pós-Graduação em Geografia.

KAPLINSKY, Raphael et al. (2003). The global wood furniture value chain: what prospects for upgrading by developing countries - the case of South Africa. Vienna: UNIDO.

LIMA, E. \& CARVALHO JR., M. de (2000). “Ações para acelerar a expansão das exportações". Revista do BNDES 7(14): 253-272.

LIMA, E. \& CARVALHO JR., M. de \& ROSA, J. (1999). "Definindo alvos para a promoção de exportações”. BNDES Setorial 9: 135-160.

NADVI, K. \& SCHMITZ, H. (1997). SME responses to global challenges: case studies of private and public initiatives. Seminar on New Trends and Challenges in Industrial Policy, Vienna: UNIDO, Oct.

PAMPLONA, Pedro (2001). Modelo setorial integrado de internacionalização de empresas brasileiras - cadeias produtivas: o caso Promóvel. Florianópolis: Dissertação de Mestrado, Universidade Federal de Santa Catarina, Programa de Pós-Graduação em Engenharia de Produção.

QUINTAR, Aida et al. (1993). Rafaela: un quasi-distrito italiano "a la argentina". Progetto Finalizzato CNR "Il sistema delle politiche e dei servizi reali per la proiezione internazionale del sistema produttivo italiano", Roma, Università di Roma "Tor Vergata".

ROSA, S. da \& CORREA, A. \& LEMOS, M. \& BARROSO, D. (2007). “O setor de móveis na atualidade: uma análise preliminar”. BNDES Setorial 25: 65106.

SCHMITZ, Hubert (1995). "Collective efficiency: growth path for small-scale industry”. The Journal of Development Studies 31(4):529-566.

SEABRA, F. \& PAUlA, D. de \& FORMAGGI, L. (2005). Arranjo produtivo de móveis da região de São Bento do Sul. Programa Estratégico de Desenvolvimento com Base na Inovação: Relatório Geral. Florianópolis: UFSC/PPGE/NEITEC, out.

SZAPIRO, M. \& ANDRADE, M. (2002). “Internacionalização de arranjos e sistemas de MPME”. In LASTRES, H. et al. (Coords.) Interagir para competir: promoção de arranjos produtivos e inovativos no Brasil. Brasília: SEBRAE: FINEP: CNPq, pp. 225-248.

VALENÇA, A. \& PAMPLONA, L. \& SOUTO, S. (2002). "Os novos desafios para a indústria moveleira no Brasil”. BNDES Setorial 15: 83-96.

Recebido em: 04 de julho de 2007

Primeira resposta em: 31 de julho de 2007

Aceito em: 23 de agosto de 2007 
GUIMARÃES,P. \& LINS,H. Promovendo exportações de móveis: aspectos da implementação ...

Anexo

QUADRO A1 - EMPRESAS ENTREVISTADAS NO AGLOMERADO MOVELEIRO DE SÃO BENTO DO SUL - JANEIRO DE 2007

\begin{tabular}{|c|c|c|c|}
\hline Empresa & Município & Empregos & Produtos \\
\hline Móveis Imperial & $\begin{array}{l}\text { São Bento do } \\
\text { Sul }\end{array}$ & 70 & $\begin{array}{l}\text { Móveis de madeira para } \\
\text { dormitórios; partes de móveis }\end{array}$ \\
\hline $\begin{array}{l}\text { Móveis Katzer } \\
\text { Ltda. }\end{array}$ & $\begin{array}{l}\text { São Bento do } \\
\text { Sul }\end{array}$ & 190 & $\begin{array}{c}\text { Móveis de madeira para } \\
\text { dormitórios; outros móveis de } \\
\text { madeira; partes para móveis }\end{array}$ \\
\hline $\begin{array}{l}\text { Móveis Polska } \\
\text { Ltda. }\end{array}$ & $\begin{array}{l}\text { São Bento do } \\
\text { Sul }\end{array}$ & 165 & $\begin{array}{l}\text { Móveis de madeira para } \\
\text { dormitórios }\end{array}$ \\
\hline $\begin{array}{l}\text { Produmex Móveis } \\
\text { Ltda. }\end{array}$ & $\begin{array}{l}\text { São Bento do } \\
\text { Sul }\end{array}$ & 35 & $\begin{array}{l}\text { Espelhos de vidro emoldurados; } \\
\text { móveis de madeira para } \\
\text { dormitórios; outros móveis de } \\
\text { madeira }\end{array}$ \\
\hline $\begin{array}{l}\text { Tremóvel } \\
\text { Indústria de } \\
\text { Móveis Ltda. }\end{array}$ & $\begin{array}{l}\text { São Bento do } \\
\text { Sul }\end{array}$ & 70 & $\begin{array}{c}\text { Móveis de madeira para } \\
\text { dormitórios; outros móveis de } \\
\text { madeira }\end{array}$ \\
\hline $\begin{array}{l}\text { Herli Ind. e Com. } \\
\text { de Móveis Ltda. }\end{array}$ & Rio Negrinho & 160 & $\begin{array}{c}\text { Móveis de madeira para } \\
\text { dormitórios e cozinhas; outros } \\
\text { móveis de madeira }\end{array}$ \\
\hline $\begin{array}{l}\text { Fábrica de Móveis } \\
\text { Rio Negrinho Ltda. }\end{array}$ & Rio Negrinho & 230 & $\begin{array}{c}\text { Móveis de madeira para } \\
\text { escritórios, cozinhas e } \\
\text { dormitórios; outros móveis de } \\
\text { madeira }\end{array}$ \\
\hline $\begin{array}{l}\text { Peale Ind. e Com. } \\
\text { de Móveis Ltda. }\end{array}$ & Rio Negrinho & 86 & $\begin{array}{l}\text { Móveis de madeira para } \\
\text { escritórios e dormitórios; outros } \\
\text { móveis de madeira; partes para } \\
\text { móveis }\end{array}$ \\
\hline $\begin{array}{l}\text { Normóveis Ind., } \\
\text { Com. e Partic. } \\
\text { Ltda. }\end{array}$ & Campo Alegre & 83 & $\begin{array}{c}\text { Espelhos de vidro emoldurados; } \\
\text { móveis de madeira para cozinhas } \\
\text { e dormitórios; outros móveis de } \\
\text { madeira }\end{array}$ \\
\hline
\end{tabular}

